\title{
Phototactic behavior 9: phototactic behavioral response of Tribolium castaneum (Herbst) to light-emitting diodes of seven different wavelengths
}

\author{
Jaeun Song ${ }^{1} \cdot$ Eun-Young Jeong $^{1} \cdot$ Hoi-Seon Lee $^{1}$ (D)
}

Received: 7 January 2016 / Accepted: 16 February 2016 / Published Online: 30 June 2016

(C) The Korean Society for Applied Biological Chemistry 2016

\begin{abstract}
The phototactic behavioral responses of Tribolium castaneum adults to light-emitting diodes (LEDs) of seven different wavelengths were determined under various conditions (light exposure times, light sources, and luminance intensities) and compared with those of a black light bulb (BLB) under laboratory conditions. Based on the attractive rate (\%) of T. castaneum adults under optimal conditions (50 lx and an $48 \mathrm{~h}$ exposure time) in the dark, red LED $(625 \pm 10 \mathrm{~nm})$ exhibited the highest potential attractive rate $(97.8 \%)$, followed by yellow $(590 \pm 5 \mathrm{~nm}, 68.9 \%)$, green $(520 \pm 5 \mathrm{~nm}, 55.6 \%)$, infrared (IR) $(730 \mathrm{~nm}, 54.4 \%)$, white (450-620 nm, $41.1 \%$ ), blue ( $470 \pm 10 \mathrm{~nm}, 34.4 \%$ ), and ultraviolet (UV) (365 nm, $0.06 \%$ ) LEDs. In comparison, red LED (97.8 \%) was approximately 3.4 times more attractive to $T$. castaneum adults than the BLB $(28.9 \%)$. These results indicate that a red LED trap could be useful to control $T$. castaneum adults.
\end{abstract}

Keywords Attraction effects $\cdot$ Light-emitting diodes $\cdot$ Phototactic response $\cdot$ Tribolium castaneum

Stored foods/grains are damaged by various stored food/grain insects such as beetle pests, mites, and moths, resulting in qualitative and quantitative losses (Rajendran and Sriranjini 2008). Stored food/grain pests contribute to contamination of food/grain commodities through the presence of dead insects,

Hoi-Seon Lee $(\bowtie)$

E-mail: hoiseon@jbnu.ac.kr

${ }^{1}$ Department of Bioenvironmental Chemistry, College of Agriculture \& Life Science, Chonbuk National University, Jeonju 54896, Republic of Korea

This is an Open Access article distributed under the terms of the Creative Commons Attribution Non-Commercial License (http://creativecommons. org/licenses/by-nc/3.0/) which permits unrestricted non-commercial use, distribution, and reproduction in any medium, provided the original work is properly cited. chemical excretions, and insect body fragments. The major insect in stored foods/grains is the red flour beetle, Tribolium castaneum (Herbst) (Coleoptera: Tenebrionidae) (Golebiowska 1969). T. castaneum adults cause both qualitative and quantitative damages to flour by feeding, and they are a very common pest in flour mills, warehouses, and grocery stores (Garcia et al. 2005). It is the most economically important crop pest and has a worldwide distribution (Padin et al. 2002). Therefore, controlling the red flour beetles relies on the use of fumigants and conventional insecticides, such as chlorfluazuron and methyl bromide (Kim and Lee 2013). The use of conventional insecticides for the control of stored food/ grain insects has been decreased because of problems with exposure to famers, ozone depletion, and stored food/grain pest resistance (Paul and Zlatko 2000). Thus, there is a growing need for alternative insect control methods for T. castaneum.

Non-chemical systems are attractive since they neither leave chemical residues in the food/grain and commodity nor do they cause resistance in insect pests (Padin et al. 2002). Among the non-chemical systems, light-emitting diode (LED) traps have been extensively used to control insect pests, including Liriomyza trifolii and Trialeurodes vaporariorum (Kim and Lee 2013). The specific merits of LEDs such as high mechanical stability, long operating life, low cost, low temperature, weight, and sensitivity have made LEDs an alternative to conventional insecticides for stored insect pests (Schubert 2003). Therefore, in the present study, the behavioral effects of LEDs on attracting $T$. castaneum adults under laboratory conditions were examined and compared with the commonly used black light bulb (BLB).

\section{Stored insects}

The cultures of $T$. castaneum were provided from the National Academy of Agricultural Science (Jeonju, Korea). These insects were reared in incubators on wheat flour + yeast $(10: 1)$, in rearing containers $(30 \times 30 \times 25 \mathrm{~cm})$ at $30 \pm 1{ }^{\circ} \mathrm{C}$ and $60 \pm 10 \%$ RH. Only adult insects were used for the phototactic behavioral tests. 


\section{LED sources}

LED sources were provided from Ciel Light Co. (Seoul, Korea) and Kodenshi Auk Co. Ltd (Jeonbuk, Korea). The LEDs chosen for testing were as follows: ultraviolet (UV) $(360 \mathrm{~nm})$, blue (470 nm, CL-1W-UBB, 15.0 $\pm 3.1 \mathrm{~lm}$ ), green (520 nm, CL-1W-UPGB, $45.0 \pm 3.5 \mathrm{~lm}$ ), yellow (590 nm, PP592-8L61-AOBI, 40.0 \pm 10.0 $\mathrm{lm})$, white (450-620 nm, CL-1W-URB, $60.0 \pm 4.6 \mathrm{~lm})$, red $(625$ $\mathrm{nm}, \mathrm{CL}-1 \mathrm{~W}-\mathrm{URB}, 35.0 \pm 1.2 \mathrm{~lm})$, and infrared (IR) $(730 \mathrm{~nm})$. The behavioral effects of the LEDs to red flour beetles were compared with those of the BLB (F8T5 BLB: Sankyo-Denki Co. Ltd., Tokyo, Japan). The LED boards were attached to a control circuit board $(30 \times 14 \mathrm{~cm})$ in a chamber. The intensity and wavelength of LEDs were controlled by control circuit board.

\section{Chamber}

The test chamber was constructed using a modified Y-maze made by $\mathrm{Oh}$ and Lee (2011). The Y-maze was made of an opaque acrylic body $(\mathrm{W} 40 \times \mathrm{D} 40 \times \mathrm{L} 20 \mathrm{~cm})$ and two acrylic walls that were situated at both ends of the interface on a light arm to allow the light passage. The outside of the light arm was set up the light sources at a distance of $25 \mathrm{~cm}$. The entrance hole $(10 \mathrm{~cm})$ was situated between the dark arm and the light arm, and covered with nylon netting cloth. The Y-maze chamber was maintained at $60 \pm 5 \% \mathrm{RH}$ and $27 \pm 0.5^{\circ} \mathrm{C}$.

\section{Bioassay}

The phototactic responses of the $T$. castaneum adults to LEDs were examined in the chamber under different illuminance intensities, wavelengths, and light-exposure time. The illuminance intensity (lx) of the LEDs at the starting point (60 $\mathrm{cm}$ from the light source) was determined using an illuminometer (LM-332; AS ONE Co. Ltd., Tokyo, Japan). Thirty T. castaneum adults were collected, and released through the entrance hole. To examine the phototactic responses of the light, the numbers of beetles in the light arm and dark arm of the Y-maze chamber were recorded. First, the attractive effects of the $T$. castaneum adults to five different wavelengths were examined at four illuminance intensities $(25,50,75$, and 100 $\mathrm{lx})$. In the second, the light durations $(12,24,36,48$, and $60 \mathrm{~h})$ were measured under the optimal lighting conditions. Finally, the behavioral responses of $T$. castaneum adults to each LED were repeatedly measured under optimal conditions (exposure time and luminance intensity). These results were compared with those of the BLB. All experiments were repeated six times. One-way analyses of variance (ANOVA) using SPSS statistical software (version 18.0, SPSS Inc., Chicago, Illinois, USA) was used to compare the numbers of $T$. castaneum adults in the phototactic responses. Duncan's multiple-range test was performed to compare differences among the mean values at $p<0.05$. Data were expressed as means \pm standard error of the mean (SEM).

To evaluate the phototactic behavioral patterns of the $T$. castaneum adults to the LEDs, the attractive effects (\%) of five luminous intensities, seven wavelengths of monochromatic light, and five light-exposure times were compared to that of the BLB, which served as the positive control. The behavioral pattern of $T$. castaneum adults to the five LEDs (blue, green, yellow, red, and white) under four luminance intensities $(25,50,75$, and $100 \mathrm{~lx})$ at a $48 \mathrm{~h}$ light-exposure time are shown in Table 1. Among the LEDs of five different wavelengths at a $48 \mathrm{~h}$ light-exposure time, red $(625 \pm 10 \mathrm{~nm})$ was the most attractive $(87.8,97.8,90.0$, and $83.9 \%$ ) to the $T$. castaneum adults at each luminance intensity

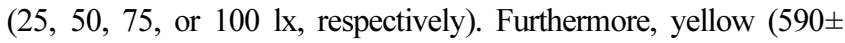
$5 \mathrm{~nm})$, green $(520 \pm 5 \mathrm{~nm})$, white $(450-620 \mathrm{~nm})$, and blue $(470 \pm$ $10 \mathrm{~nm}$ ) LEDs at a $48 \mathrm{~h}$ light-exposure time exhibited 68.9, 55.6, 41.1 , and $34.4 \%$ attractive rates at $50 \mathrm{~lx}$, respectively. However, at 25,75 , or $100 \mathrm{~lx}$ luminance intensity, red, yellow, green, white, and blue LEDs showed low attractive responses.

The attractive rates of the T. castaneum adults to the LEDs of seven different wavelengths (UV, blue, green, yellow, red, white, and IR) and five light-exposure times (12, 24, 36, 48, and $60 \mathrm{~h}$ ) were examined at optimal luminous intensity (50 lx) (Table 2). At $50 \mathrm{~lx}$ luminance intensity, red $(625 \pm 10 \mathrm{~nm})$ LED was the most attractive $(65.6,83.9,83.3,97.8$, and $89.1 \%)$ to the $T$. castaneum adults at each $12,24,36,48$, or $60 \mathrm{~h}$ light-exposure time, respectively. Red LED exhibited the highest attractive effect ( $97.8 \%$ ), followed by yellow (68.9\%), green (55.6\%), IR (54.4\%), white (41.1\%), blue $(34.4 \%)$, and UV (5.6\%) LEDs at a $48 \mathrm{~h}$ light-exposure time. No significant differences were observed in the attraction rates $(\%)$ of the $T$. castaneum adults at 36,48 , or $60 \mathrm{~h}$ light

Table 1 Attractive rates of Tribolium castaneum adults to light emitting diodes (LEDs) under four luminance intensities (lx) $)^{1)}$

\begin{tabular}{|c|c|c|c|c|}
\hline \multirow{3}{*}{ Wavelength (color) } & \multicolumn{4}{|c|}{ Attractive rate $(\%)^{2)}$} \\
\hline & \multicolumn{4}{|c|}{ Luminance intensity (lx) } \\
\hline & 25 & 50 & 75 & 100 \\
\hline $470 \pm 10 \mathrm{~nm}$ (Blue) & $27.7 \pm 1.87^{\text {bc }}$ & $34.4 \pm 2.08^{b c}$ & $20.0 \pm 1.45^{\mathrm{bc}}$ & $8.0 \pm 0.99^{c}$ \\
\hline $520 \pm 5 \mathrm{~nm}$ (Green) & $15.6 \pm 1.13^{\mathrm{c}}$ & $55.6 \pm 1.96^{b}$ & $44.4 \pm 2.82^{\mathrm{bc}}$ & $43.3 \pm 2.89^{\mathrm{bc}}$ \\
\hline $590 \pm 5 \mathrm{~nm}$ (Yellow) & $31.7 \pm 2.10^{\mathrm{bc}}$ & $68.9 \pm 2.43^{\mathrm{ab}}$ & $63.3 \pm 2.97^{\mathrm{ab}}$ & $12.2 \pm 1.61^{\mathrm{c}}$ \\
\hline $625 \pm 10 \mathrm{~nm}(\mathrm{Red})$ & $87.8 \pm 2.84^{\mathrm{a}}$ & $97.8 \pm 2.79^{a}$ & $90.0 \pm 2.83^{\mathrm{a}}$ & $83.9 \pm 2.65^{\mathrm{ab}}$ \\
\hline $450-620 \mathrm{~nm}$ (white) & $6.7 \pm 0.88^{c}$ & $41.1 \pm 2.35^{b c}$ & $13.3 \pm 1.59^{\mathrm{c}}$ & $13.9 \pm 1.73^{\mathrm{c}}$ \\
\hline
\end{tabular}

\footnotetext{
${ }^{1)}$ Each value is the average of 6 determinations after a $48 \mathrm{~h}$ exposure, with 30 adult insects per replication
}

${ }^{2)}$ Attractive rate $(\%)$ is the average percentage of the $30 \mathrm{~T}$. castaneum adults attracted to four light intensities 
Table 2 Attractive rates of $T$. castaneum adults to LEDs under various light-exposure times (h) ${ }^{1)}$

\begin{tabular}{|c|c|c|c|c|c|c|}
\hline \multirow{3}{*}{ Wavelength (color) } & \multirow{3}{*}{$\begin{array}{l}\text { Luminance } \\
\text { intensity (lx) }\end{array}$} & \multicolumn{5}{|c|}{ Attractive rate $(\%)^{2)}$} \\
\hline & & \multicolumn{5}{|c|}{ Light-exposure time (h) } \\
\hline & & 12 & 24 & 36 & 48 & 60 \\
\hline $365 \mathrm{~nm}$ (UV) & $-3)$ & $2.8 \pm 0.49^{c}$ & $4.4 \pm 0.54^{\mathrm{c}}$ & $4.9 \pm 0.70^{c}$ & $5.6 \pm 0.62^{\mathrm{c}}$ & $5.2 \pm 0.92^{\mathrm{c}}$ \\
\hline $470 \pm 10 \mathrm{~nm}$ (Blue) & 50 & $16.1 \pm 0.68^{c}$ & $17.2 \pm 0.70^{\mathrm{c}}$ & $18.9 \pm 0.77^{\mathrm{c}}$ & $34.4 \pm 2.12^{\mathrm{bc}}$ & $33.4 \pm 1.46^{\mathrm{bc}}$ \\
\hline $520 \pm 5 \mathrm{~nm}$ (Green) & 50 & $44.4 \pm 2.44^{\mathrm{b}}$ & $45.6 \pm 2.51^{\mathrm{b}}$ & $47.8 \pm 1.27^{\mathrm{bc}}$ & $55.6 \pm 2.67^{\mathrm{ab}}$ & $52.3 \pm 1.52^{\mathrm{bc}}$ \\
\hline $590 \pm 5$ nm (Yellow) & 50 & $22.2 \pm 0.44^{\mathrm{c}}$ & $32.2 \pm 2.09^{\mathrm{bc}}$ & $57.8 \pm 2.67^{\mathrm{ab}}$ & $68.9 \pm 2.87^{\mathrm{ab}}$ & $64.5 \pm 1.89^{\mathrm{bc}}$ \\
\hline $625 \pm 10 \mathrm{~nm}(\mathrm{Red})$ & 50 & $65.6 \pm 2.84^{\mathrm{ab}}$ & $83.9 \pm 2.74^{\mathrm{ab}}$ & $87.3 \pm 2.69^{\mathrm{ab}}$ & $97.8 \pm 2.93^{\mathrm{a}}$ & $96.1 \pm 1.77^{\mathrm{a}}$ \\
\hline 450-620 nm (white) & 50 & $11.1 \pm 0.27^{\mathrm{c}}$ & $12.2 \pm 0.41^{\mathrm{c}}$ & $18.3 \pm 1.57^{\mathrm{bc}}$ & $41.1 \pm 2.14^{b c}$ & $40.9 \pm 2.83^{b c}$ \\
\hline 730 nm (IR) & $-3)$ & $19.4 \pm 1.68^{\mathrm{bc}}$ & $21.1 \pm 1.39^{\mathrm{bc}}$ & $21.7 \pm 1.88^{\mathrm{bc}}$ & $54.4 \pm 2.62^{\mathrm{b}}$ & $53.4 \pm 2.27^{\mathrm{b}}$ \\
\hline
\end{tabular}

${ }^{1)}$ Each value is the average of 6 determinations, with 30 adult insects per replication

${ }^{2)}$ Attractive rate $(\%)$ is the average percentage of the $30 \mathrm{~T}$. castaneum adults attracted to five light-exposure times

${ }^{3)}$ Each value is the average of 6 determinations per each light-exposure time at $8 \mathrm{~W}$

Table 3 Attractive rates of T. castaneum to the LEDs of seven different wavelengths and BLB under optimal lighting conditions ${ }^{1)}$

\begin{tabular}{|c|c|c|c|c|}
\hline \multirow{2}{*}{ Wavelength (color) } & \multicolumn{2}{|c|}{ Number of insects (Mean \pm SEM) } & \multirow{2}{*}{ Attractive rate $(\%)^{3)}$} & \multirow{2}{*}{ Relative attraction $^{4}$} \\
\hline & Light choice & No choice & & \\
\hline $365 \mathrm{~nm}$ (UV) & $1.67 \pm 0.69^{c}$ & $20.19 \pm 2.92$ & $0.06^{\mathrm{c}}$ & 0.2 \\
\hline $470 \pm 10 \mathrm{~nm}$ (Blue) & $10.33 \pm 1.42^{\mathrm{bc}}$ & $6.33 \pm 1.40$ & $34.4^{\mathrm{c}}$ & 1.2 \\
\hline $520 \pm 5 \mathrm{~nm}$ (Green) & $16.67 \pm 3.25^{\mathrm{b}}$ & $9.83 \pm 1.66$ & $55.6^{\mathrm{b}}$ & 1.9 \\
\hline $590 \pm 5 \mathrm{~nm}$ (Yellow) & $20.67 \pm 3.43^{\mathrm{ab}}$ & $8.17 \pm 1.43$ & $68.9^{\mathrm{ab}}$ & 2.4 \\
\hline $625 \pm 10 \mathrm{~nm}(\mathrm{Red})$ & $29.33 \pm 1.64^{\mathrm{a}}$ & $-2)$ & $97.8^{\mathrm{a}}$ & 3.4 \\
\hline 450-620 nm (white) & $12.30 \pm 2.06^{\mathrm{b}}$ & $7.34 \pm 1.41$ & $41.1^{\mathrm{bc}}$ & 1.4 \\
\hline $730 \mathrm{~nm}(\mathrm{IR})$ & $16.33 \pm 2.49^{\mathrm{b}}$ & $5.67 \pm 1.13$ & $54.4^{\mathrm{b}}$ & 1.9 \\
\hline BLB & $8.67 \pm 1.49^{\mathrm{bc}}$ & $21.81 \pm 2.63$ & $28.9^{c}$ & 1.0 \\
\hline
\end{tabular}

${ }^{1)}$ Each value is the average of 6 determinations at optimal conditions (50 lx and $48 \mathrm{~h}$ ), with 30 adult insects per replication

${ }^{2)}$ Each value is the average of 6 determinations per each light-exposure time at $8 \mathrm{~W}$

${ }^{3)}$ Attractive rate $(\%)$ is the average percentage of the 30 T. castaneum adults attracted under optimal conditions

${ }^{4)}$ Relative attraction = attractive rate of each wavelength/attractive rate of the BLB

duration for each optimal exposure time. These results indicate that UV LED showed lower phototactic behavioral response to the T. castaneum adults at optimal conditions. In a previous study, Antignus (2000) suggested that a UV trap reduced the incidence of three insect pests: Frankliniella occidentalis, Bemisia tabaci, and Liriomyma trifolii.

Based on the results presented in Tables 1 and 2, the attractive patterns of the $T$. castaneum adults to the LEDs of seven different wavelengths (UV, blue, green, yellow, red, white, and IR) were evaluated at $50 \mathrm{~lx}$ luminous intensity and a $48 \mathrm{~h}$ light-exposure time and compared with those to the BLB (Table 3). Red LED showed the highest attractive rate $(97.8 \%)$, followed by yellow $(68.9 \%)$, green $(55.6 \%)$, IR $(54.4 \%)$, white $(41.1 \%)$, blue $(34.4 \%)$, BLB (28.9\%), and UV (0.06\%) LEDs. The visible (blue, green, yellow, red, and white) LEDs were approximately 1.2 to 3.4 times more attractive to the $T$. castaneum adults than the BLB. In previous studies, Jeon et al. (2012) suggest that blue $(84.3 \%)$ LED was the most attractive to Sitophilus oryzae (L.), the rice weevil, followed by green (74.3\%), red (64.3\%), and UV (63.3\%) LEDs. Moreover, green and the blue LEDs were 1.3 and
1.5 times more attractive than the BLB, respectively. In this regard, our results indicate that the phototactic behavioral responses of the $T$. castaneum adults depend on the luminance, specific wavelength, and light exposure time.

A number of insects have blue, green, and UV photoreceptors in their eyes (Briscoe and Chittka 2001). Vaishampayan et al. (1975) observed a phototactic response of Trialeurodes vaporariorum (Westwood) to yellow-green (520-610 nm) and ultraviolet (360$380 \mathrm{~nm}$ ) illuminance. In the case of $T$. castaneum adults, Jackowska et al. (2007) suggest that long wavelength (LW) opsin-expressing photoreceptors show sensitivities ranging between 480 and 600 $\mathrm{nm}$ and that the $T$. castaneum adults have a single LW-opsin across the entire retina. The fact that $T$. castaneum adults showed greater sensitivity in red wavelength may be due to LW-opsin of the retina. Taken together, our study results suggest that red LED $(625 \pm 10 \mathrm{~nm})$ at $50 \mathrm{~lx}$ luminous intensity and a $48 \mathrm{~h}$ exposure time was the most suitable in attracting $T$. castaneum adults for protecting stored foods/grains. However, further experimental research is necessary to compare the efficiencies of the selected LEDs. 
Acknowledgments This work was carried out with the support of "Cooperative Research Program for Agriculture Science \& Technology Development (Project title: Development of integrated pest management techniques using natural products and LEDs in the grain storage, Project No PJ01004501)" Rural Development Administration, Republic of Korea.

\section{References}

Antignus Y (2000) Manipulation of wavelength-dependent behaviour of insects: an IPM tool to impede insects and restrict epidemics of insectborne viruses. Virus Res 71: 213-220

Briscoe AD, Chittka L (2001) The evolution of color vision in insects. Ann Rev Entomol 46: 471-510

Garcia M, Donadel OJ, Ardanaz CE, Tonn CE, Sosa ME (2005) Toxic and repellent effects of Baccharis salicifolia essential oil on Tribolium castaneum. Pest Manag Sci 61: 612-618

Golebiowska Z (1969) The feeding and fecundityof Sitophilus granarius (L.), Sitophilus oryzae (L.) and Rhyzopertha dominica (F.) in wheat grain. J Stored Prod Res 5: 143-155

Jackowska M, Bao R, Liu Z, McDonald EC, Cook TA, Friedrich M (2007) Genomic and gene regulatory signatures of cryptozoic adaptation: Loss of blue sensitive photoreceptors through expansion of long wavelengthopsin expression in the red flour beetle Tribolium castaneum. Front Zool
4: $1-11$

Jeon JH, Oh MS, Cho KS, Lee HS (2012) Phototactic response of the rice weevil, Sitophilus oryzae linnaeus (Coleoptera: Curculionidae), to lightemitting diodes. J Korean Soc Appl Biol Chem 55: 35-39

Kim MG, Lee HS (2013) Attractive effects of American serpentine leafminer, Liriomyza trifolii (Burgess), to light-emitting diodes. J Insect Behav 27: 127-132

Oh MS, Lee HS (2011) Development of phototactic test apparatus equipped with light source for monitoring pests. J Appl Biol Chem 53: 248-252

Padin S, Dal BG, Fabrizio M (2002) Grain loss caused by Tribolium castaneum, Sitophilus oryzae and Acanthoscelides obtectus in stored durum wheat and beans treated with Beauveria bassiana. J Stored Prod Res 38: 69-74

Paul F, Zlatko K (2000) The effect of grain moisture content and temperature on the efficacy of diatomaceous earths from different geographical locations against stored-product beetles. J Stored Prod Res 36: 1-13

Rajendran S, Sriranjini V (2008) Plant products as fumigants for storedproduct insect control. J Stored Prod Res 44: 126-135

Schubert EF (2003) Light-emitting diodes, Cambridge University Press, 0521-82330, UK

Vaishampayan SM, Kogan M, Waldbauer GP, Wooley JT (1975) Spectral specific responses in the visual behaviour of the greenhouse whitefly, Trialeurodes vaporariorum (Homoptera: Aleurodidae). Entomol Exp Appl 18: 344-356 